\title{
Europe Looks into the Mirror
}

\section{Breen, Michael J. (ed.) (2017): Values and identities in Europe: Evidence from the European Sacial Survey. London and New York: Routledge. 314 pages.}

The year 2002 is a turning point in the almost fifty-year-long history of international comparative surveys. After years of preparation this was the first time that 22 European countries participated in the data collection of the European Social Survey (ESS). Naturally, there have been other surveys before with several countries participating: the Eurobarometer surveys that covered all the member states at that time started in 1973, the World Values Survey in 1981, the International Social Survey Program (ISSP) in 1984 - just to name a few. As social sciences became more and more international, several similar initiatives were started in the past one or two decades that mainly covered larger cultural-political regions or aimed at a wider focus in the world (e.g. European Values Study, Latinobarómetro, Afrobarometer, Asian Barometer, Pew Global Attitudes Project, etc.).

The ESS stands out from several aspects. First of all, it has become one of the official research infrastructures of the European Union (European Research Infrastructure Consortium - ERIC), with a background of governmental support of the participating countries, and a professional central management consisting of members of acknowledged universities and research institutions. This exceptional organizational background assures that the biannual data collection is implemented with extraordinary precision and continuous quality assurance. As the Hungarian coordinator of ESS, I have first-hand experience and can safely state that from a methodological point of view, there is no better source of survey data suitable for international comparison at present. The international conferences and the number of publications that are based on its data prove that ESS has become a first-class brand in the field of international comparative social research.

In 2015 there was an ESS conference at the Mary Immaculate College of Ireland. The presentations were edited by Michael J. Breen and published by Routledge under the title Values and Identities in Europe: Evidence from the European Social Survey in 2017. Naturally, the contents of this book do not cover the entirety of the topics surveyed in ESS, but the contributions give a fair overview of the most important fields and results. Generally speaking, the writings of the book follow the same characteristic strategies most studies on international surveys do. The first group contains analyses that confine themselves to one country (despite the possibilities of international comparison). Writings in the second group compare all the available data (for example all the data of the European countries available in ESS) or a selection of the data of several countries. The third group has studies that use 
several sources of data, either by including macrodata of countries or bigger regions in their models for a multilevel analysis, or by using the results of more than one survey (in this case the ESS and some other surveys).

Anyone interested in the history, significance, or scientometric indicators of the ESS can learn a lot from the introductory study of the editor, Michael J. Breen. For example, that Hungary is one of the few 'elite' countries where all the ESS data collection rounds have been implemented so far. By the time the work on Round 8 was finished in the autumn of 2017, almost 15000 Hungarians, the population of a small town had participated with their answers to the success of the ESS. Another important detail is that the full, unrestricted databases of the ESS are used by 60000 students and 18000 researchers all over the world and have been instrumental in more than $7000 \mathrm{PhD}$ dissertations.

Following the introductory study there are five more or less consistent chapters that contain 15 further studies. The first chapter contains papers related to religion. 'The Declining Significance of Religion: Secularization in Ireland' by Ryan T. Cragun outlines the secularizing trends, mainly focusing on Ireland. Anna Kulkova's writing ('Religiosity and Political Participation across Europe') offers a wider perspective on the topic by examining the connection between political participation and religiousness in the European countries. Her contribution is an excellent example for a quantitative study that tries to find a causal link between two social phenomena using the widest level of analysis (in this case, among countries). The usual challenge of such research is whether these (mostly weak) statistical connections exist in reality. One wonders what the intermediate factors (variables) are that should also be taken into account, but either we do not have data for them, or if we do, we do not consider these for some reason. And the most exciting question: can we determine the direction of the casual link; can we be sure which social phenomenon is the cause and which is the effect? As for Kulkova's study, what can we do with the result that Protestants are somewhat more active politically than Catholics, but this connection is only true in some of the countries, and countries that have an orthodox religious majority are prone to have a lower level of political activity? One does not need to have a keen sense of research and analysis to know that this population mostly overlaps with the population of the countries with one-party domination, which has determined their political socialization.

Thus, it would seem logical to say that first-hand political experience is more relevant in this case than religious traditions. (It is a different question whether the social values determined - partly - by religion played a role in the long rule of despotic regimes.) In these cases, the phenomena are obviously more complex and we cannot draw a straight line from religiousness to political activism. It is important to mention that the author is also aware of these limitations, but it is an excellent example of the problems for anybody who would try to study such a complex question based on empirical data in just ten pages. The last study of the first chapter ('Religion and Values in the ESS' by Caillin Reynolds) examines the correlations of religiousness and value systems with the help of multi-level regression analysis. One of the most important statements of the study is that religion in itself strongly affects one's value system, and the wider social climate of the country also has a similar effect. The latter is one of the most important determining factors of basic cultural norms. 
The analysis uses items of the Human Values Inventory, which has been part of the ESS standard questionnaire from the beginning and is thus the most extensive 'quality' source for data on human values.

The second chapter is about social identity. One of the rarities of the book is that four Hungarian authors (Dániel Oross, Andrea Szabó, Ivett Szalma and Judit Takács) contributed in three studies. This shows that even though the number of Hungarian researchers who use ESS data is not very high when compared to other European countries, those that do are very active in publication. The first Hungarian contribution is a piece by Michael Ochsner and Ivett Szalma ('Work-Life Conflict of Working Couples Before and During the Crisis in 18 European Countries'), that deals with the change of gender roles, the division of labour at home, and the conflict of work and private life. The analysis uses a massive statistical apparatus and answers several research questions of the topic, but its most interesting result is that the increase in work-related stress affected even those who managed to keep their jobs despite the crisis, and this correlation was present even in countries that were much less affected by economic recession.

The analysis of Amy Erbe Healy and Seán Ó Riain with the long title 'A Tale of Two Surveys: Using European Social Survey and European Working Conditions Survey to Predict Welfare Attitudes by Work Regime' follows the strategy mentioned above. It uses two independent sources of data to predict welfare attitudes in various work organizational regimes. The method is basically a comparison of the results of the two data sources.

Marguerite Beattie's study 'Societal-Level Equality and Well-Being' seeks for a correlation between social equality and welfare and includes variables like justice and trust. The author uses the ESS data from between 2002 and 2012 and the Gini coefficient from the OECD, but the results are not very exciting, the applied method and the conclusions could be questioned from various points of view.

The third chapter of the book also includes three writings on political identity and safety. Krystina Chabova's highly promising study, 'Corruption in European Countries: A Cross-National Comparison' adopts a macro perspective to examine the topic. The author is interested in the correlations of income inequality, economic development, the ratio of members of Protestant churches, the quantity of general trust, and the level of corruption in the given country. Corruption is an extremely complex social phenomenon and the means of quantifying it and compressing it into a simple index or explaining it by a causal link has long been the aim of social sciences and policy type research. Even though there is no perfect solution for the task, all experiments are interesting and edifying. Chabova does not examine very complex questions; she merely tests the well-known hypotheses using the data of ESS. The analysis is unique because at the level of statistics models and interpretation it separates European countries into post-Communist and non-post-Communist groups and thus reveals differences that would have stayed in the dark with an overall European approach. The results show that the (mainly 'Western') hypotheses proved to be true in the countries without a Communist past, but the correlations are not that clear in the Eastern part of Europe. For example, the higher amount of trust or the lower levels of income inequality do not decrease corruption in these countries. 
Two Hungarian authors, Dániel Oross and Andrea Szabó examine the political participation of the youth of four countries: Belgium, Austria, Switzerland and Hungary in their study 'Changing Tendencies of Youth Political Participation in Europe: Evidence from Four Different Cases'. Each of these countries represent a unique model: voting has been obligatory in Belgium since 1892, Austria decreased the age of voting to 16 in 2007, Switzerland is unique in its traditions of direct democracy, and Hungary is an interesting case because the socialisation of political processes is still strongly determined by the post-Communist heritage. The authors used the participation in elections and the forms of voicing and acting out their political opinions as independent variables in their analysis. The results show that the political participation of the youth of these four countries follows different patterns. In Belgium and Austria, the participation of the youth is almost as high, or even higher than that of adults. In Switzerland and Hungary non-electoral participation is lower among the young. This is mainly true for Hungary, where it is so low that it can hardly be measured among the young. One of the main statements of the study is that nonelectoral participation can mainly be explained by individual variables, whereas participation in elections is more determined by wider social and political factors.

The study of Aoife Prendergast ('Untangling our Attitudes Towards Irish Citizen Involvement and Democracy') focuses on the Irish case. Based on ESS data it shows how democracy (democracy-related attitudes) correlates with higher education (the content of the training). The main message of the author is that education (in social sciences) is essential if we aim to have citizens who are capable of implementing democracy. Obviously, this statement could or should be heard by several other countries, as well.

The studies of the fourth chapter on family also discuss various topics. Alexandra Lipasova's piece deals with Russia ('Fatherhood in Russia: Fertility Decisions and Ideational Factors'). It focuses on the 'masculinity crisis' of Russian men that is brought about by changing gender roles. While women can apply for traditionally male roles (career, business success, etc.), males who would undertake female roles (staying home with the children, taking up traditionally female jobs, etc.) are still strongly stigmatized.

In Mare Ainsaar's analysis ('Well-Being in Married and Cohabiting Families with Children and Social Support during Economic Recession in Europe') the author is treading on thin ice when trying to find a clear causal link between marriage, cohabitation, having children, and life satisfaction. The author states that couples with children have an advantage in life satisfaction and well-being, but its extent is strongly determined by the economic and social support they receive from their country. Another statement of the study is that marriage can be the source of a higher amount of satisfaction than other forms of cohabitation. As before, the problem with such statements is that they do not seem to be able to differentiate which factor is the cause and which is the effect. Reality tends to be more complex than the scope of a narrow statistical analysis.

The last study of the chapter is the work of Hungarian authors ('How to Measure Fathering Practices in a European Comparison?'). Ivett Szalma and Judit Takács examined the change of male and female roles in Europe. The analysis is unique because it is based on both ESS and EVS (European Value Study) data, so it is 
remarkable from the aspect of international comparative research methodology. Although there is no exact correspondence between the two datasets, the results show the same trends. Among others, gender-related attitudes and expectations have changed significantly in Europe - and Hungary is no exception.

The last chapter of the book contains writings on ESS methodology. Helge Baumann examines the most significant challenge of questionnaire surveys: nonresponse. The analysis narrows down the question to just one variable ('How important do you think it is for democracy in general that the government protects all citizens against poverty?') and two countries (Germany and Ireland). The main dilemma of such research is whether the attitude and socio-demographic profile of those who refused to answer is significantly different from that of the other interviewees.

Brendan Halpin and Michael J. Breen write about the possibilities of combining datasets ('Combining Multiple Datasets for Simultaneous Analysis on the Basis of Common Identifiers'). Using various imputation models, their analysis examines opportunities for merging ESS and EVS datasets that were applied together in several other studies. It is beyond the scope of this review to discuss their results in detail, but it is definitely an exciting and unavoidable possibility of the future.

Finally, Ana Villar and Rory Fitzgerald, members of the central management team of ESS, report on the experience of mixed data collection. It is important to mention that ESS has been very active in experimenting and at the same time canonizing, as the crisis of the traditional ways of data collection is more and more evident. A legitimate methodology of data collection must be found that can react to the changes of technology and the growing demotivation of the interviewees. Meanwhile, it guarantees a high standard collection of (nearly) identical quality data in very heterogeneous cultural, social and economic environments.

All in all, Values and Identities in Europe is an exciting intellectual adventure in the world of international comparative research that reveals some of the most current ideas and trends in social sciences and the methodological challenges of research.

BENCE SÁGVÁRI (sagvari.bence回tk.mta.hu) Centre for Sacial Sciences, Hungarian Academy of Sciences 